Research paper

\title{
Depression with melancholic features is associated with higher long-term risk for dementia
}

\author{
Frederico Simões do Couto ${ }^{\mathrm{a}, \mathrm{b}, *}$, Nuno Lunet $^{\mathrm{c}, \mathrm{d}}$, Sandra Ginó ${ }^{\mathrm{a}}$, Catarina Chester ${ }^{\mathrm{a}}$, \\ Vanda Freitas $^{\mathrm{a}}$, Carolina Maruta ${ }^{\mathrm{a}}$, Maria Luísa Figueira ${ }^{\mathrm{b}}$, Alexandre de Mendonça ${ }^{\mathrm{a}}$ \\ a Dementia Study Group, Institute of Molecular Medicine, Faculdade de Medicina, Universidade de Lisboa, Portugal \\ ${ }^{\mathrm{b}}$ Psychiatry and Psychology Department, Faculdade de Medicina, Universidade de Lisboa, Portugal \\ c Department of Clinical Epidemiology, Predictive Medicine and Public Health, Faculty of Medicine, University of Porto, Porto, Portugal \\ ${ }^{\mathrm{d}}$ EPIUnit - Institute of Public Health, University of Porto, Porto, Portugal
}

\section{A R T I C L E I N F O}

\section{Article history:}

Received 9 March 2016

Received in revised form

30 April 2016

Accepted 17 May 2016

Available online 26 May 2016

\section{Keywords:}

Dementia

Depression

Melancholia

Hypothalamus-Hypophysis-adrenal axis

Risk factor

\begin{abstract}
A B S T R A C T
Background: Depression has been reported to increase the risk of subsequently developing dementia, but the nature of this relation remains to be elucidated. Depression can be a prodrome/manifestation of dementia or an early risk factor, and the effect may differ according to depression subtypes. Our aim was to study the association between early-onset depression and different depression subtypes, and the later occurrence of dementia.

Methods: We conducted a cohort study including 322 subjects with depression, recruited between 1977 and 1984. A comparison cohort (non-exposed) was recruited retrospectively, to include 322 subjects admitted at the same hospital for routine surgery (appendicectomy or cholecystectomy), at the same period as the depressed cohort. Subjects were contacted again between 2009 and 2014, to assess their dementia status. We computed the risk for dementia in subjects with early onset depression and quantified the association between different depression subtypes (namely melancholic, anxious, and psychotic) and dementia.

Results: The odds of dementia were increased by 2.90 times (95\% C.I. $1.61-5.21 ; \mathrm{p}<0.0001$ ) for the depressed cohort when compared to the surgical cohort. When the analysis was restricted to patients younger than 45 years old at baseline, the odds for dementia in the depressed cohort were also significantly higher when compared to the surgical cohort (8.53; 95\% C.I. 2.40-30.16). In the multivariate Cox analysis, subjects having depression with melancholic features had an increased risk for developing dementia compared to those without melancholic features (HR=3.64; 95\% C.I. 1.78-11.26; $p=0.025)$.

Limitations: About $59 \%$ of the participants with depression and $53 \%$ of those non-exposed were lost during follow up. The inclusion of biological biomarkers would strengthen the results. The sample included a low number of bipolar patients.

Conclusions: These results support depression as an early risk factor for dementia. Depression with melancholic features was found as an important risk factor for dementia, playing a main role in the relation between these disorders.
\end{abstract}

(c) 2016 Elsevier B.V. All rights reserved.

\section{Introduction}

As most dementing conditions are irreversible, and the available therapies have limited beneficial effects, primary prevention of cognitive decline is of paramount importance (Ritchie et al., 2010; Norton et al., 2014). Among the several risk factors so far identified, depression emerges as a potentially important target

\footnotetext{
* Corresponding author at: Dementia Study Group, Institute of Molecular Medicine, Faculdade de Medicina, Av. Prof. Egas Moniz, 1649028 Lisboa, Portugal.

E-mail address: fcouto@medicina.ulisboa.pt (F. Simões do Couto).
}

(Reitz et al., 2011), because is amenable to prevention, has a high prevalence, and can be diagnosed inexpensively and treated effectively (Kupfer et al., 2012; Malhi et al., 2015).

Depression has been found to be a risk factor for dementia or Alzheimer's dementia (AD) in several case-control (Cooper and Holmes, 1998; Green et al., 2003) and cohort studies (DalForno et al., 2005; Kessing and Nilsson, 2003; Saczynski et al., 2010; Irie et al., 2008; Dotson et al., 2010; Byers and Yaffe, 2011), but not all (Chen et al., 1999, 2008; Gatz et al., 2005; Brommelhoff et al., 2009). The meta-analyses and reviews performed have confirmed this association in general, finding that depression approximately doubles the risk for dementia (Jorm, 2001; Ownby et al., 2006; 
Silva et al., 2013).

However, the nature of this relation remains poorly understood. Two unsolved issues have been repeatedly raised (Byers and Yaffe, 2011; Kessing, 2012). The first is that depression, especially if occurring after 60 years old (called late onset depression) or next to the diagnosis of dementia, can be a prodrome/manifestation of a dementing disorder, instead of an early risk factor. Depressive symptoms are quite common in dementia, and depressive symptoms may arise from the anatomic lesions that are part of the neuropathological changes of dementing disorders (Boland, 2000). Case-control studies that do not take in account the time between dementia and depression diagnosis, and cohort studies with a short follow up, may not be able to distinguish between these two situations. The few studies that specifically compared late-onset depression with early-onset depression found discrepant results (Green et al., 2003; Geerlings et al., 2008; Brommelhoff et al., 2009; Lenoir et al., 2011; Almeida et al., 2016).

The second issue is the subtype of depression. The heterogeneity of depression has seldom been taken into account. A more severe disorder (expressed by higher frequency, duration, and severity of the depressive episodes) has been inconsistently associated with a higher risk for dementia (Kessing and Andersen, 2004; Geerlings et al., 2008; Kessing, 2012; Silva et al., 2013). Bipolar disorder has also been associated with a higher risk of dementia. In the review and meta-analysis by Silva et al. (2013) the majority of studies confirmed the association in accordance with subsequent published studies. Brodaty et al. (2003) explored the role of comorbid anxiety in depression on the risk for dementia and found no influence. On the other hand, the use of benzodiazepines has been reported to carry a higher risk (Billioti de Gage et al., 2012). Psychotic symptoms have been associated with a higher risk for cognitive deficits only in bipolar patients (MartínezArán et al., 2004). Few studies looked at the risk for dementia in DSM5 or ICD10 defined depression subtypes. DalForno et al. (2005), in a community based study, performed an additional risk analysis finding that a Center for Epidemiologic Study-Depression (CES-D) sub-scale based on a cluster of negative affective symptoms, related to melancholic features, did not influence the global risk for dementia. Different biological mechanisms underlying these different depressive conditions can carry different risks for dementia. Melancholic features, and to a lesser extent psychotic symptoms, have been associated with more consistent biological abnormalities and response to treatment (Brown, 2007; Parker et al., 2013) when compared to their absence.

These unsolved issues - prodrome versus early risk factor and the heterogeneity of depression - regarding the risk for dementia in depressed patients, encouraged us to perform the current study. The objectives were to assess the association between early-onset depression and the long-term risk for dementia, and to analyze the risk for dementia of different depression subtypes, controlling for well known risk factors for dementia.

\section{Methodology}

\subsection{Study design}

This study is based on two cohorts followed in average 25 years for development of dementia. The exposed cohort (depression cohort) comprised 325 patients from the Hospital de Santa Maria, Lisbon, with the clinical diagnosis of depression, recruited between 1977 and 1984 in a taxonomic cluster analysis study of depression (Paes de Sousa et al., 1980).

A surgical comparison cohort (non-exposed) was recruited retrospectively, to include 325 subjects who were consecutively admitted to Hospital de Santa Maria, Lisbon, for routine surgery (appendicectomy or cholecystectomy) at the same period as the depressed cohort.

Participants were re-evaluated between 2009 and 2014, to establish the outcome - dementia status.

\subsection{Baseline assessment}

Data on demography, clinical history, and personal and family history as part of routine clinical files were collected for both cohorts. For the depressed cohort a comprehensive psychiatric and psychological evaluation was performed.

\subsubsection{Evaluations}

2.2.1.1. Association for methodology and documentation in psychiatry system (AMDP). The AMDP-System was created in Nuremberg in 1960 and has been widely used in Europe in 1970-1980. The Psychopathology Scale contains 100 psychopathology items, including symptoms and other clinical features, derived from classic psychopathology studies from Jaspers, Bleuler, Schneider, and others. It renders a very detailed and standardized evaluation, including affective, behavioral, cognitive, psychotic, sensory, and social dimensions of psychopathology (Busch et al., 1980; Paes de Sousa et al., 1980).

Each symptom is scored for severity (0-3: absent, mild, moderate, severe).

This evaluation notably allowed the classification of depression by virtually any diagnostic system and has been used for diagnostic or reclassification purposes with other diagnostic systems, such as the DSM IV (Salvatore et al., 2007; Seemüller et al., 2008).

2.2.1.2. Eysenck personality questionnaire (EPQ). This questionnaire (Eysenck and Eysenck, 1975) includes 83 items (full version), allowing the evaluation of the three basic personality dimensions, according to Eysenck's personality theory: extroversion, neuroticism and psychoticism. Only the extroversion and neuroticism dimensions were analyzed in this study. The subject responds yes or no, and a positive answer is scored 1 . The final result is the sum of the points in each scale (0-23 for extroversion and $0-23$ for neuroticism)

The neuroticism dimension assesses emotional stability versus instability and identifies individuals prone to psychological distress. Low scores indicate a trend to more relaxed, unemotional, and self-satisfied subjects. The extraversion dimension measures interpersonal interaction, activity level, need for stimulation, and capacity for joy. The subjects with a low score tend to be more reserved, sober, task-oriented, and quiet.

A low extroversion (a score lower then median) and high neuroticism group (a score higher than median) of subjects was created, as these subjects were previously found to be at a higher risk for dementia (Wang et al., 2009).

2.2.1.3. Clinical global impression (CGI)). Clinical global impression - severity (CGI S; Guy, 1976) is 7-point scale to evaluate the current severity of the patient's illness, according to the clinician's total past experience, ranging from 1 (not at all ill) to 7 (extremely ill).

\subsubsection{Diagnosis of depression}

Using AMDP symptoms at baseline, DSM 5 diagnostic criteria for Persistent Depressive Disorder (dysthymia), Major Depressive Disorder (MDD), melancholic and psychotic features were applied. Through baseline chart review, subjects were considered to have bipolar disorder if they met DSM 5 criteria for bipolar disorder.

The specifier of anxious distress could not be defined by AMDP as only two anxious symptoms ("psychic anxiety" and "somatic anxiety") are present in the scale. A numerical variable "anxiety symptoms" was created adding both scores. Chronic disease was 


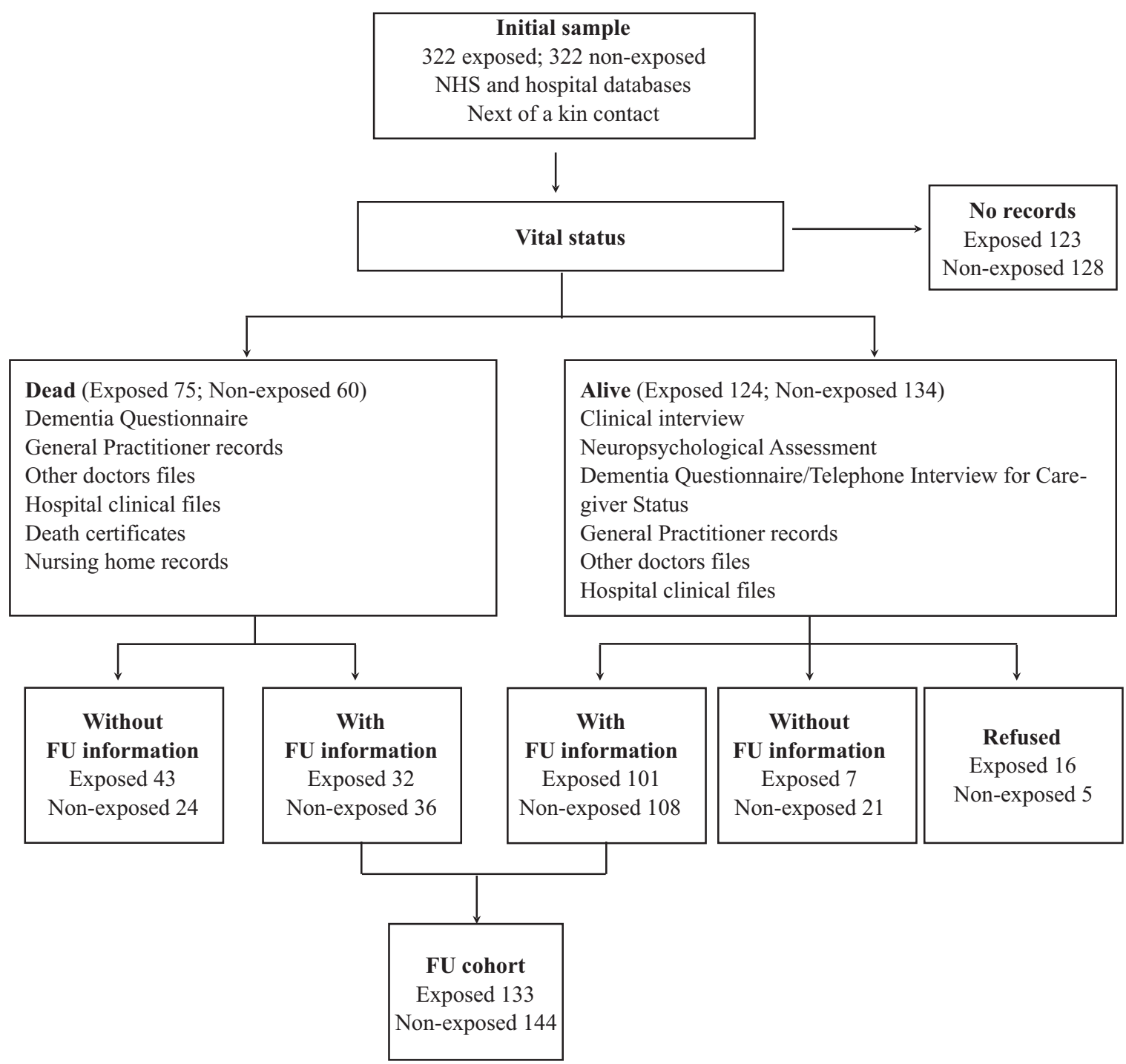

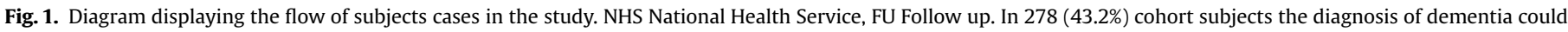
be established or excluded. The rates of follow up in relation to death are $42.7 \%$ in the exposed group and $60.0 \%$ in the non-exposed group.

defined if MDD symptoms were present continuously for more than two years.

\subsection{Follow-up}

\subsubsection{Follow up procedures}

The Hospital de Santa Maria, the Institute of Notaries and Records, and the National Health Service databases were contacted to get the subjects' address and next of kin, phone number, vital status, General Practitioner (GP) and other relevant doctors' names. This search allowed to find and contact subjects, or next of kin if the subject was dead.

2.3.1.1. Depressed cohort. Based on the information gathered during the follow-up, the initial diagnosis was reviewed and 3 patients were excluded from the depressed cohort because the diagnosis of depression was found wrong, namely one had schizophrenia, another schizoaffective disorder and the third a brain tumor. So, the depressed cohort recruited 322 subjects (Fig. 1).

It was not possible to ascertain the vital status of 123 subjects (no records found, data illegible or too many records found for a given name).

In the remaining 199 (61.2\%), additional information was sought to establish a diagnosis of dementia. In the 75 subjects found to be dead, the next of kin was contacted to collect demographic information and to apply the Dementia Questionnaire (DQ). GP records, psychiatrist records, neurologist records, hospital clinical files, death certificates and nursing home records were reviewed to collect information regarding dementia diagnosis. In 43 subjects no contact with next of kin was possible or the clinical information in clinical files was not enough to establish or exclude the diagnosis of dementia.

The 124 alive subjects were contacted first by mail, presenting the study and indicating that a later phone contact would be done. Then, a clinical interview and a neuropsychological assessment were offered. If a subject was living far away, too ill to be submitted to neuropsychological assessment, or not willing to come for the clinical/neuropsychological assessment, telephone interviews (Telephone Interview for Cognitive Status (TICS) and/or DQ) to evaluate the cognitive status were applied. Patient's GPs, or other relevant doctors were contacted, and hospital records reviewed when appropriate. No contact at all was possible and no clinical records were found in 7 subjects, and a total of 16 subjects refused to participate in the study. In 133 (41.3\%) subjects the outcome could be established (Fig. 1). 
2.3.1.2. Surgical cohort. For the non-exposed cohort, we followed the methodology of a similar study (Brodaty et al., 2003). The first 325 subjects who were admitted for routine appendectomy or cholecystectomy at the same period as cases, and who could be matched to cases for age ( \pm 2 years) and sex were identified from surgical lists (Fig. 1). For each depressed subject, the first identified matched control in the surgical list was assessed for his/her eligibility status. A subject was considered eligible if a mood disorder was not present prior to or at the time of index surgical hospitalization. This assessment was made by the review of the subject clinical files at the index hospitalization, and a diagnosis of a mood disorder and prescription of antidepressants, mood stabilizers or antipsychotics were considered exclusion criteria. A further assessment was performed at follow up by direct questioning. Three subjects were excluded from the surgical cohort, because they were found to be depressed $(n=2)$ or to have a diagnosis of bipolar disorder $(n=1)$ at inclusion time. The surgical (non-exposed) cohort included 322 subjects.

Identical procedures were taken to assess their dementia status as with the depressed participants. It was possible to ascertain the vital status of 128 subjects (60.2\%). Among these, 5 refused to participate in the study, and in 45 the diagnosis of dementia could be not confirmed or excluded. The diagnosis of dementia could be established or excluded in 144 subjects (44,3\%).

2.3.2. Follow up assessment (evaluations performed in 2009-2014) 2.3.2.1. Neuropsychological assessment. A comprehensive evaluation was performed, either at patients' home or in the hospital, by experienced neuropsychologists. The evaluation included (1) Battery of Lisbon for the Assessment of Dementia (BLAD; Garcia, 1984), (2) Trail Making Test - parts A and B (TMT; Reitan, 1958), (3) Toulouse-Piéron Test (TP; Toulouse and Piéron, 1986; Mendelsohn, 2000), and (4) California Verbal Learning Test (CVLT; Delis et al., 1987; Ribeiro et al., 2007).

\subsubsection{Other assessments}

1) Telephone Interview for Cognitive Status (TICS)

This instrument (Brandt et al., 1988; Madureira et al., 2006) was initially developed for the assessment of AD patients unwilling or unable to return for follow-up. It gathers information on the domains of orientation, concentration, short-term memory, mathematical skills, praxis and language. It was proven to be sensitive and specific, and to have high test-retest reliability. The cutoff used for dementia was less than 26.

2) Dementia Questionnaire (DQ)

The Dementia Questionnaire (Silverman et al., 1986) is applied by telephone to caregivers of patients with dementia allowing to quickly diagnose dementia in patients by the DSM IIIR criteria, and in some cases even to suggest the dementia subtype. The DQ can also be applied to care givers of already dead patients with dementia. A validated version including the age of onset of dementia and dementia subtype was used (Teixeira et al., 2011).

3) Vascular risk factors assessment

Subjects with a previous diagnosis of hypertension, diabetes, dyslipidemia, ischemic heart disease or cerebrovascular disease were considered to have vascular risk factors.

\subsubsection{Diagnosis of dementia}

Dementia was diagnosed at a case conference, including a psychiatrist (F.S.doC.), a neurologist (A.deM.) and a neuropsychologist (C.C.), all experienced in dementia. Cases were determined based on the best available information, using DSM-5 criteria for Major Neurocognitive Disorder (dementia) (American
Psychiatric Association, 2013).

Clinical and neuropsychological assessment information were reviewed. If a subject was dead or did not attend the formal evaluation, case conference reviewed all the available evidence. In these cases, the diagnosis of dementia was based on at least two of the following: TICS score of 26 or less; DQ yielded a diagnosis of dementia; GPs records with a diagnosis of dementia; a diagnosis of dementia performed by either a neurologist or a psychiatrist; hospital records of dementia; death certificate with a diagnosis of dementia; retrospective case audit to meet DSM-5 dementia criteria; diagnosis of dementia recorded in nursing-home notes. If a diagnosis of dementia was established, reference to a Dementia Clinics was offered to the subject, to undergo the standard of care for evaluation and treatment of dementia.

The type of dementia was determined in the case conference referred above, using all the available information. The criteria for the diagnosis of the most common types of dementia were used: probable Alzheimer's disease according to NINCDS-ADRDA criteria (McKhann et al., 2011), probable vascular dementia according to NINDS-AIREN criteria (Roman et al., 1993), probable dementia with Lewy bodies (DLB) according to the criteria proposed by McKeith et al. (2005), and behavioral variant of frontotemporal dementia (FTD) according to the criteria of the International Behavioral Variant FTD Criteria Consortium (Rascovsky et al., 2011). If none of these criteria was met, or no sufficient information could be gathered, the diagnosis made was dementia non-otherwise specified (NOS). Date of onset of dementia was determined during the clinical interview, by $\mathrm{DQ}$ or chart review.

\subsection{Statistical analysis}

IBM SPSS Statistics for Windows, version 19.0 (IBM Corp, Armonk, NY, 2010) and Stata Statistical Software: Release 11 (StataCorp LP, College Station, TX, 2009) were used for the statistical analysis.

Baseline characteristics were compared between subjects in whom the outcome was assessed and in those lost during followup, using independent samples t Student's test for continuous variables, after verification of homogeneity of variances, and Pearson Chi-square test for categorical variables, with Yates continuity correction for $2 \times 2$ tables.

We used a binary logistic regression analysis (with the dependent variable constituted by the conversion to dementia during the follow-up period) to compute the odds ratio (OR) for the associations between depression and dementia. Because data on age of dementia onset in the non-exposed cohort were available only in a minority of subjects, it was not possible to perform a Coxregression analysis in this group.

Cox proportional hazards models were used to compute crude and adjusted hazard ratios (HR) and 95\% confidence intervals (95\% CI) to quantify the relation between the different exposures, including depression subtypes, and dementia. For multivariate analyses we considered the variables that were significantly associated $(\mathrm{p}<0.05)$ with dementia in univariate analysis (baseline age, depression with melancholic features, depression with anxiety symptoms, and severity of the index episode (CGI)), as well as variables considered to be potentially relevant confounding factors (sex, years of education, bipolar disorder, depression with psychotic features, and chronic disorder), according to the literature (Kessing and Andersen, 2004; Ritchie et al. 2010; Reitz et al., 2011; Silva et al., 2013). Age of onset and the presence of vascular risk factors were considered only in sensitivity analyses because data on these variables was available for a subset of all patients (77 and 123 , respectively), and due to the fact that the latter was assessed at follow-up. For each participant the follow-up started at the date of diagnosis of depression, or corresponding index data in the 
surgical cohort, and ended at the estimated data of onset of dementia, date of follow-up assessment or date of death, whichever occurred first, as applicable. The proportional hazards assumption was evaluated graphically using "log-log" plots.

The cumulative incidence of dementia was estimated, across the follow-up period, taking into account the competing risk of death, using a competing-risks regression model, according to the method of Fine and Gray (Fine and Gray, 1999).

Statistical significance was accepted for $\mathrm{p}<0.05$.

\subsection{Ethics}

This study was conducted in accordance with the Helsinki Declaration as well as national ethical guidelines. The local Ethics Committee, the National Data Protection Committee, and the National Institute of Notaries and Records approved the protocol. Subjects who performed follow up evaluation were required to provide informed consent. If a diagnosis of dementia was established, reference to a Dementia Clinics was offered to the subject, to undergo the standard of care for evaluation and treatment of dementia.

\section{Results}

Comparing baseline data of the subjects with and without a known outcome, the mean age was lower in both cohorts, and the proportion of men was smaller in the subjects with a known outcome only in the depressed cohort. No statistically significant differences were observed regarding other socio-demographic and clinical characteristics (Table 1). Almost all subjects were Cauca$\operatorname{sian}(98 \%)$.

\subsection{Depression as a risk factor for dementia}

Forty-four (22.3\%) of the 133 subjects from the depressed cohort developed dementia, compared to 21 (14.6\%) of the 144 subjects from de surgical cohort. Dementia cause could be assessed in about half of the cases (in 21 and 8 subjects, depressed and surgical respectively). The most prevalent cause in both groups was Alzheimer's disease (AD) (57\% and 63\%), followed by vascular dementia (19\% and 25\%), and Parkinson's disease (14\% only in the depressed cohort). Other causes, found only in one patient each, were vitamin B12 deficiency and HIV dementia in the depressed cohort and neurosyphilis in the surgical cohort.
The characteristics of subjects who developed dementia and those that have not are displayed in Table 2. At follow-up 4 patients were rediagnosed as bipolar, due to a later emergence of a manic episode, and 2 non bipolar patients fulfilled DSM5 criteria for Persistent Depressive Disorder at baseline, but were re-classified later as MDD.

A logistic binary regression analysis showed that the odds of dementia were increased by 2.90 times (95\% C.I. 1.61-5.21; $\mathrm{p}<0.0001$ ) for the depressed cohort when compared to the surgical cohort. The higher risk for dementia in the depressed cohort was still significant after adjusting for sex, age, and education years $(\mathrm{OR}=3.36$; 95\% C.I. 7.76-6.80; $\mathrm{p}<0.0001)$.

\subsection{Depression as an early risk factor}

To address the issue of depression as a prodrome of dementia we repeated the analysis considering the subjects with an early onset of depression and those with a longer time frame between the two diagnoses. The definition of the age limit of late onset depression varies across the studies, between the age of 45 (Steffens et al., 1997) and the age of 60 years (Byers and Yaffe, 2011). When the analysis was restricted to patients younger than 45 , or 60 years old at baseline, the odds for dementia in the depressed cohort were still significantly higher when compared to the surgical cohort (8.53; 95\% C.I. 2.40-30.16 and 3.30; 95\% C.I. 1.75-6.33, for those younger than 45 and 60, respectively). When adjusting for age, sex, and education years, similar results were found (8.69; 95\% C.I. 2.21-34.23 and 4.00; 95\% C.I. 1.87-8.60, for those younger than 45 and 60 , respectively).

Age of depression onset was only available in 77 subjects. In those with depression onset before the age of 60 the odds of developing dementia were not different for those with depression onset after the age of $60(0.84 ; 95 \%$ C.I. $0.38-1.84)$, even after controlling for age, sex, and education years (0.72; 95\% C.I. 0.30 1.74).

A 10 years difference between depression diagnosis and dementia onset has been used as a criterion to reduce the risk of misdiagnosing depression as prodrome of dementia (Brunnström et al., 2013). When restricting the analysis to the subjects with a follow up time longer than 10 years (94.0\% in the exposed group and $97.9 \%$ in the non-exposed group), depression still emerged as a risk factor for dementia when compared to the surgical cohort (2.95; 95\% C.I. $1.62-5.40$ and 4.16; 95\% C.I. $1.96-8.83$, for crude and adjusted OR, respectively).

Table 1

Baseline characteristics of both cohort subjects to known outcome.

\begin{tabular}{|c|c|c|c|c|c|c|c|c|}
\hline & \multicolumn{4}{|l|}{ Depressive cohort } & \multicolumn{4}{|l|}{ Surgical cohort } \\
\hline & $\begin{array}{l}\text { Lost during follow } \\
\text { up }(n=189)\end{array}$ & $\begin{array}{l}\text { With known out- } \\
\text { come }(n=133)\end{array}$ & $\begin{array}{l}\text { Total } \\
(\mathrm{n}=322)\end{array}$ & $p$ Value $^{a}$ & $\begin{array}{l}\text { Lost during follow } \\
\text { up }(n=178)\end{array}$ & $\begin{array}{l}\text { With known out- } \\
\text { come }(n=144)\end{array}$ & $\begin{array}{l}\text { Total } \\
(\mathrm{n}=322)\end{array}$ & $p$ Value $^{a}$ \\
\hline Age, mean (SD), y & $50.8(12.7)^{\mathrm{b}}$ & $41.8(11.6)$ & $46.9(13.0)$ & $<0.001$ & $47.7(14.5)$ & $41.0(12.1)$ & $44.6(13.8)$ & $<0.001$ \\
\hline Male sex, \% (n) & $27.0 \%(51)$ & $15.0 \%(20)$ & $22.0 \%(71)$ & 0.014 & $24.2 \%(43)$ & $19.4 \%(28)$ & $22.0(71)$ & 0.212 \\
\hline Education, mean (SD), y & $6.4(4.6)$ & $7.1(4.5)$ & $6.7(4.6)$ & 0.165 & N.A. & $6.63(4.6)^{c}$ & & \\
\hline Bipolar disorder, \% (n) & $10.6 \%(20)$ & $16.5 \%(22)$ & $13.0 \%(42)$ & 0.326 & & & & \\
\hline Melancholic features, \% (n) & $33.3 \%(63)$ & $35.3 \%(47)$ & $34.2 \%(110)$ & 0.722 & & & & \\
\hline Psychotic features, \% (n) & $24.3 \%(46)$ & $24.1 \%(32)$ & $24.2 \%(78)$ & 0.999 & & & & \\
\hline $\begin{array}{l}\text { Anxiety symptoms severity, } \\
\text { mean (SD) }\end{array}$ & $1.6(2.6)$ & $1.9(2.8)$ & $1.7(2.7)$ & 0.288 & & & & \\
\hline $\begin{array}{l}\text { Clinical Global Impression } \\
\text { (CGI), mean (SD) }\end{array}$ & $5.0(0.8)$ & $5.0(0.7)$ & $5.1(0.7)$ & 0.978 & & & & \\
\hline
\end{tabular}

N.A. not available. Education years were not written in most surgical files.

${ }^{a}$ Comparing, within each cohort, those with a known outcome with those without known outcome, based on chi-square test for category variables and independent samples $t$ test for continuous variables.

b Baseline age available only for 182 subjects.

c Education years available for 111 subjects. 
Table 2

Cohort characteristics and outcome.

\begin{tabular}{|c|c|c|c|c|}
\hline & \multicolumn{2}{|l|}{ Depressed cohort } & \multicolumn{2}{|l|}{ Surgical cohort } \\
\hline & Non-demented $(\mathrm{n}=89)$ & Demented $(n=44)$ & Non-demented $(\mathrm{n}=123)$ & Demented $(\mathbf{n}=\mathbf{2 1})$ \\
\hline Age, mean (SD), y & $38.9(10.4)$ & $47.8(11.5)$ & $37.7(11.0)$ & $54.2(9.1)$ \\
\hline$<35$ years, \% (n) & $46.1 \%(41)$ & $11.4 \%(5)$ & $48.8 \%(60)$ & $0.0 \%(0)$ \\
\hline $35-45$ years, \% (n) & $23.6 \%(21)$ & $29.5 \%(13)$ & $22.8 \%(28)$ & $14.3 \%(3)$ \\
\hline$>45$ years, \% (n) & $30.3 \%(27)$ & $59.1 \%(26)$ & $28.5 \%(35)$ & $85.7 \%(18)$ \\
\hline Male \% (n) & $14.6 \%(13)$ & $15.9 \%(7)$ & $19.5 \%(24)$ & $19 \%(4)$ \\
\hline Education, mean (SD), $\mathbf{y}^{\mathrm{a}}$ & $7.8(4.5)$ & $5.9(4.4)$ & $7.3(4.7)$ & $2.9(1.7)$ \\
\hline$<5$ years, \% $(n)$ & $39.3 \%(35)$ & $61.4 \%(27)$ & $48.4 \%(59)$ & $85.7 \%(18)$ \\
\hline 5-9 years, \% (n) & $31.5 \%(28)$ & $22.7 \%(10)$ & $14.8 \%(18)$ & $0.0 \%(0)$ \\
\hline$>9$ years, \% $(\mathbf{n})$ & $29.2 \%(26)$ & $15.9 \%(7)$ & $36.9 \%(45)$ & $14.3 \%(3)$ \\
\hline Follow up time, mean (SD), y & $26.3(7.2)$ & $24.5(7.3)$ & $29.0(6.8)$ & $25.1(7.6)$ \\
\hline Age of onset of the disorder, mean (SD), $y^{b}$ & $28.4(10.2)$ & $34.8(10.2)$ & & \\
\hline Bipolar disorder, \% (n) & $14.6 \%(13)$ & $18.2 \%(8)$ & & \\
\hline DSM5 Diagnosed MDD, \% (n) & $84.3 \%(75)$ & $79.5 \%(35)$ & & \\
\hline Melancholic features, \% (n) & $24.7 \%(22)$ & $56.8 \%(25)$ & & \\
\hline Psychotic features, \% (n) & $20.2 \%(18)$ & $31.8 \%(14)$ & & \\
\hline Anxiety symptoms severity, mean (SD), AMDP score & $1.48(2.59)$ & $2.86(2.95)$ & & \\
\hline Clinical Global Impression (CGI), mean (SD) & $4.9(0.7)$ & $5.1(0.7)$ & & \\
\hline Chronic Disorder, \% (n) & $71.3 \%(57)$ & $92.3 \%(36)$ & & \\
\hline Inpatient at baseline, \% (n) & $55.1 \%(49)$ & $65.9 \%(29)$ & & \\
\hline Ever been admitted for depression, $\%(\mathbf{n})^{\mathrm{C}}$ & $82.7 \%(62)$ & $94.6 \%(35)$ & & \\
\hline Suicide attempts, $\%(\mathbf{n})^{\mathrm{d}}$ & $43.9 \%(25)$ & $66.7 \%(12)$ & & \\
\hline EPQ (Extroversion), mean (SD) ${ }^{\mathrm{e}}$ & $38.0(21.2)$ & $35.1(17.5)$ & & \\
\hline EPQ (Neuroticism), mean (SD) ${ }^{\mathrm{e}}$ & $81.8(14.9)$ & $78.8(14.8)$ & & \\
\hline High Neuroticism/Low Extroversion Group, \% (n) ${ }^{\mathrm{e}}$ & $24.6 \%(14)$ & $23.3 \%(7)$ & & \\
\hline Vascular risk factors, $\%(n)^{f}$ & $59.8 \%(52)$ & $80.6 \%(29)$ & $61.2 \%(63)$ & $76.9 \%(10)$ \\
\hline Age of dementia onset $(y)$, mean (SD) & & $72.3(8.8)$ & & $81.5(8.5)$ \\
\hline Died, \% (n) & $18.0 \%(16)$ & $36.4 \%(16)$ & $19.5 \%(24)$ & $57.1 \%(12)$ \\
\hline
\end{tabular}

MDD Major Depressive Disorder, EPQ Eysenck Personality Questionnaire.

a Data available only in 111 controls.

${ }^{b}$ Data available only in 77 subjects.

c Data on admission status was available in 82 subjects.

d 58 subjects had suicide data.

e 87 subjects had baseline EPQ

${ }^{f}$ Data obtained at follow up, available in 123 depressed and in 116 surgical subjects.

\subsection{Role of depression heterogeneity}

In the depressed cohort, the probability of dementia increased significantly with age, was not influenced by education and was significantly higher for melancholic features, anxiety symptoms, and severity of the episode assessed with the CGI, in the univariate
Cox regression analysis (Table 3). In the multivariate Cox analysis (Table 3), older subjects at baseline and those with depression with melancholic features had an increased risk for developing dementia compared to those without melancholic features $(\mathrm{HR}=3.64 ; 95 \%$ C.I. 1.78-11.26). The other depression characteristics and education were not associated with a higher risk for

Table 3

Depressed cohort: association between demographic variables, clinical characteristics and other well established risks for dementia, and the risk of dementia.

\begin{tabular}{|c|c|c|c|c|}
\hline & \multicolumn{2}{|l|}{ Univariate analysis } & \multicolumn{2}{|c|}{ Multivariate analysis } \\
\hline & $\mathrm{HR}(95 \% \mathrm{CI})$ & $p$ Value & $\mathrm{HR}(95 \% \mathrm{CI})$ & $p$ Value \\
\hline \multicolumn{5}{|l|}{ Baseline age, y } \\
\hline$<35$ & 1 [reference] & & 1 [reference] & \\
\hline $35-45$ & $7.55(2.15-26.52)$ & 0.002 & $7.26(1.99-26.51)$ & 0.003 \\
\hline$>45$ & $15.17(4.55-50.58)$ & $<0.001$ & $13.18(3.72-47.50)$ & $<0.001$ \\
\hline \multicolumn{5}{|l|}{ Baseline education, y } \\
\hline $0-4$ & 1 [reference] & & 1 [reference] & \\
\hline $5-9$ & $0.88(0.42-1.84)$ & 0.730 & $1.40(0.60-3.28)$ & 0.437 \\
\hline$>9$ & $0.47(0.19-1.15)$ & 0.097 & $0.461(0.16-1.34)$ & 0.156 \\
\hline Bipolar disorder & $1.88(0.86-4.14)$ & 0.116 & $0.64(0.22-1.84)$ & 0.408 \\
\hline Melancholic features & $4.48(2.40-8.39)$ & $<0.001$ & $3.64(1.78-11.26)$ & 0.025 \\
\hline Psychotic features & $1.55(0.81-2.96)$ & 0.182 & $1.55(0.76-3.14)$ & 0.224 \\
\hline Anxiety symptoms & $1.18(1.08-1.30)$ & 0.001 & $0.97(0.82-1.22)$ & 0.969 \\
\hline Clinical Global Impression (Severity) & $1.84(1.18-2.87)$ & 0.008 & $1.19(0.74-2.36)$ & 0.345 \\
\hline Chronic disorder & $1.85(0.96-3.55)$ & 0.065 & $1.24(0.58-2.61)$ & 0.581 \\
\hline Male sex & $0.98(0.39-32.51)$ & 0.974 & & \\
\hline Inpatient at baseline & $1.01(0.53-1.92)$ & 0.980 & & \\
\hline Ever been admitted for depression & $2.20(0.51-9.52)$ & 0.290 & & \\
\hline Suicide attempts & $2.03(0.74-5.63)$ & 0.172 & & \\
\hline High Neuroticism/Low Extroversion Group & $0.71(0.33-1.82)$ & 0.568 & & \\
\hline
\end{tabular}

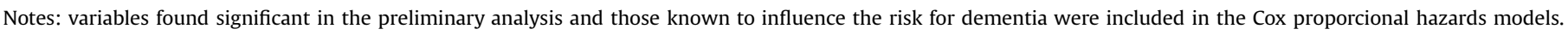




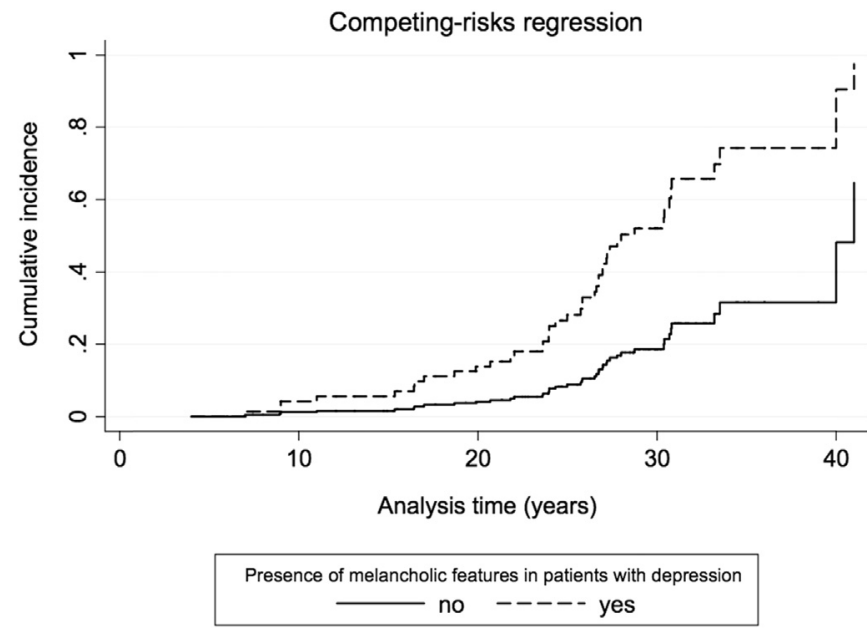

Fig. 2. Cumulative incidence of dementia, across the follow-up period, taking into account the competing risk of death, using a competing-risks regression model.

dementia.

Two sensitivity analyses were performed, including age of the affective disorder (determined in few cases) and vascular risk factors (data obtained at follow up). In a new model, the inclusion of age of affective disorder onset and vascular risk factors did not change the statistical significance of the associations between both melancholic features and age at baseline with dementia risk.

Studies with a very long follow up, especially including geriatric outcomes and depressed patients, are faced with the difficult problem of how to account for the competing risk of death (Wulsin et al., 1999). Because Cox proportional hazards regression can overestimate the risk of disease, a risk competing analysis was performed. The cumulative incidence of dementia, according to melancholic features of depression, was higher among subjects with melancholic features during most of the follow-up period, reaching approximately 50\% at around 30 years of follow-up, according to a competitive risk model (Fig. 2).

When comparing melancholic ( $\mathrm{n}=47,25$ events), non-melancholic depressed patients ( $\mathrm{n}=86,19$ events) and surgical cohort subjects ( $n=144,21$ events), logistic binary regression analysis showed a significantly increased risk for dementia only in melancholic subjects when compared to the surgical cohort subjects $(\mathrm{OR}=6.66$; 95\% C.I. $3.19-13.90$ and $\mathrm{OR}=7.72$; 95\% C.I. 3.18-18.77, for crude and adjusted for baseline age and years of education OR, respectively). Non-melancholic subjects were not at increased risk for dementia, in the same analysis $(\mathrm{OR}=1.66$; 95\% C.I. $0.84-3.31$ and 2.25; 95\% C.I. 0.99-5.10, for crude and adjusted OR, respectively).

Since the precise age of dementia onset was not possible to ascertain in about half the subjects from the surgical cohort, Cox regression analysis was not done in this cohort.

\section{Discussion}

The main finding of the present study is that melancholic features of depression are an important and independent risk factor for dementia.

Depression has been globally associated with a two-fold increase risk of dementia (Silva et al., 2013), just like we found in this study. But, as far as we know, melancholic features have not been previously specifically assessed as a risk factor for dementia. Melancholia has been associated with persistent cognitive impairment after depression remission (Lin et al., 2014; Roca et al., 2015), but not with dementia. It is possible that the follow up time has been too short in both studies ( 6 weeks and 6 months, respectively) to detect an increased incidence of dementia. Remarkably, in the present study, melancholic features were independently associated with dementia. As previously mentioned, the study from DalForno et al. (2005) failed to find an association of negative affective symptoms with dementia risk. However, the assessment of negative affective symptoms was based on a CES-D subscale which does not match exactly the standard criteria for melancholic features. Most risk factors that have been studied in previous investigations, such as more severe disorder, greater severity of the episode, diagnosis of bipolar disorder, and the presence of psychotic and anxious symptoms, were associated with an increased risk for dementia in the univariate analysis, but their significance disappeared in the multivariate analysis. Since melancholic features tend to repeat across lifetime episodes (Coryell et al., 1994), are associated with a more severe course, occur in virtually all psychotic episodes, and happen more frequently in bipolar patients (Taylor and Fink, 2008), it is possible that the higher risk associated with those characteristics in previous studies could be at least partially mediated by melancholia. However, the role of bipolar disorder as a risk factor for dementia might have been underestimated because of the small number of bipolar patients in the present cohort. Also, non-melancholic subjects were not found to be at a significantly increased risk for dementia, though results were close to statistical significance, despite the relatively small sample size in this subgroup. In any case, the present results strongly emphasize that analysis of melancholic features should be included in future studies.

There is a biological rational for the association between melancholic features and dementia, as an important body of evidence pinpoints the biological mechanisms underlying melancholia with cognitive impairment. Melancholia has been associated with hypothalamus-pituitary-adrenal (HPA) axis dysfunction (Brown, 2007; Parker et al., 2013), and hyper- and hypocortisolism characterize different subtypes of depression (Hasler et al., 2004). This HPA axis dysfunction has been widely studied in animal models and in human disorders (Lupien et al., 1998; Finsterwald and Alberini, 2013; Suzuki et al., 2014), and involves down regulation of glucocorticoid receptors and/or increased circulating glucocorticoids triggering a cascade of events that leads to cognitive impairment (McEwen and Magariños, 1997; Lupien et al., 2008). Melancholia may particularly induce hippocampal damage (Lamers et al., 2013), and has been associated with cognitive decline (Withall et al., 2010; Sachs-Ericsson et al., 2014).

Present results support a role of depression as an early risk factor for dementia, and not merely a prodrome. Our results are in line with studies with a long follow up (Kessing, 1999; Brodaty et al., 2003; Saczynski et al., 2010; Dotson et al., 2010; Barnes et al., 2012), with a low probability of misdiagnosing dementia as a depressive disorder. The few studies that specifically explored the differences between early- and late-onset depression found a very small increased risk for dementia, or no differences in early onset depression as compared to late-onset depression, however they assessed depression retrospectively by simply questioning (Green et al., 2003), using CES-D or Geriatric Depression Scale (Lenoir et al., 2011; Almeida et al., 2016), or included subjects mainly with neurotic depression (Brommelhoff et al., 2009). The accuracy of depression diagnosis was probably lower when compared to the present study, and this could have led to the inclusion of less severe depressive or non-melancholic patients.

The precise diagnosis of dementia was not possible to ascertain in about half the cases in the depressed cohort and in about $2 / 3$ of the controls, a natural consequence of the way clinical information was collected. So, it was not possible to identify whether 
depressive subtypes were associated with specific dementing disorders. It has been suggested that depression is a risk factor both for vascular dementia (VD) and for Alzheimer's disease (AD) (Lenoir et al., 2011; Brunnström et al., 2013). The Honolulu-Asia aging study (Irie et al., 2008) found a higher risk for AD, however a higher load of cortical plaques and tangles was not associated with AD and depression (Wilson et al., 2003). Although in half of the cases the dementia cause could not be identified, the present results suggest that depression would be associated essentially with an increased risk for $\mathrm{AD}$ and not VD.

This study has important strengths. It is one of longest longitudinal studies performed to evaluate the risk of dementia in depressed patients. Another strength is that the diagnosis of depression was done very reliably using an extensive and comprehensive psychiatric and psychological evaluation. The vast majority of previous studies assessed depression with rather simple instruments, such as CES-D, that cannot capture the complexity and heterogeneity of the depressive disorder. Still another strength is that important and different risk factors and confounders were assessed (such as personality, severity of the episode, or vascular risk factors), that have been seldom evaluated together. If different subtypes of depression carry different risks for dementia, it would be elicited by a study with this design.

\subsection{Limitations}

We should also note the limitations of this study. The major limitation is the large proportion of subjects without follow-up information, since only $43 \%$ of individuals included in the cohorts had follow-up data. This proportion is high, as compared to case register based studies with a complete follow-up of data on dementia and death (Kessing et al., 1999; Kessing and Nilsson, 2003). Attrition may limit the validity of findings from longitudinal studies, and is more likely to occur in investigations with long followup periods; however, the latter are essential to evaluate long-term effects and resemble more closely inception cohorts, which contributes for survival-related biases to be less likely (Saracci, 2006). Shorter studies evaluate short term effects and often include predominantly survivors instead of participants selected closer to the onset of the exposures of interest. Despite the robustness of our findings could be improved with a more complete follow-up, our design allows the evaluation of long-term effects, contributes to minimize survival-related biases and adds to previous research on this topic the assessment of the effects of different depression subtypes. Furthermore, in the present study the completeness of follow-up was greater than in other similar studies (43\% versus, for instance, 33\% in Brodaty et al. (2003)). Melancholia definition is controversial, and DSM5 definition has been challenged, on the grounds of the limitation of defining melancholia by reliance on symptoms (Parker and Paterson, 2014). These authors propose the inclusion of biological markers related to HPA dysfunction. The inclusion of a biological biomarker would strengthen the findings of this study. Another limitation is the absence of a formal cognitive evaluation at baseline. However, dementia was excluded clinically, the mean age for the onset of the affective disorder was about 35 years old and the mean time to the event was more than 25 years, making it very unlikely that dementia was present at baseline.

\subsection{Conclusions}

This study supports depression as an early risk factor for dementia, and not only a prodrome. Depression is a heterogeneous disorder, and it is possible that the frequency of melancholic features could explain the discrepancies found in the risk for depression as a whole in the different studies. Melancholic features of depression should be actively identified in the clinical setting, and DSM5 criteria seem appropriate for this purpose. Due to a more favorable response to biological therapies, appropriate treatment of melancholia could decrease the risk for dementia.

\section{Role of funding source}

This work was supported by Bolsa Barahona Fernandes (Faculty of Medicine of Lisbon). The funders had no role in the study design, collection, analysis and interpretation of the data, writing of the report, or the decision to submit the article for publication.

\section{Conflict of interest}

None.

\section{Acknowledgements}

The authors would like to express a profound and enormous gratitude to Dr. Manoel Paes de Sousa, who passed away on 2005, for a major contribution to this work, and to his widow Dr. Ilda Paes de Sousa, for providing all his research data and files.

\section{References}

Almeida, O.P., Hankey, G.J., Yeap, B.B., Golledge, J., Flicker, L., 2016. Depression as a risk factor for cognitive impairment in later life: the health in men cohort study. Int. J. Geriatr. Psychiatry 31, 412-420.

American Psychiatric Association, 2013. Diagnostic and Statistical Manual of Mental Disorders, 5th ed. American Psychiatric Publishing, Arlington, VA.

Barnes, D.E., Yaffe, K., Byers, A.L., McCormick, M., Schaefer, C., Whitmer, R.A., 2012. Midlife vs late-life depressive symptoms and risk of dementia: differential effects for Alzheimer disease and vascular dementia. Arch. Gen. Psychiatry 69, 493-498.

Billioti de Gage, S., Bégaud, B., Bazin, F., Verdoux, H., Dartigues, J.F., Pérès, K., Kurth, T., Pariente, A., 2012. Benzodiazepine use and risk of dementia: prospective population based study. BMJ 345, e6231.

Boland, R.J., 2000. Depression in Alzheimer's disease and other dementias. Curr. Psychiatry Rep. 2, 427-433.

Brandt, J., Spencer, M., Folstein, M., 1988. The telephone interview for cognitive status. Neuropsychiatry Neuropsychol. Behav. Neurol. 1, 111-117.

Brodaty, H., Luscombe, G., Anstey, K.J., Cramsie, J., Andrews, G., Peisah, C., 2003. Neuropsychological performance and dementia in depressed patients after 25 year follow-up: a controlled study. Psychol. Med. 33, 1263-1275.

Brommelhoff, J.A., Gatz, M., Johansson, B., McArdle, J.J., Fratiglioni, L., Pedersen, N.L., 2009. Depression as a risk factor or prodromal feature for dementia? Findings in a population-based sample of Swedish twins. Psychol. Aging 24, 373-384.

Brown, W.A., 2007. Treatment response in melancholia. Act. Psych. Scand. 115 (Suppl. 433), S125-S129.

Brunnström, H., Passant, U., Englund, E., Gustafson, L., 2013. History of depression prior to Alzheimer's disease and vascular dementia verified post-mortem. Arch. Gerontol. Geriatr. 56, 80-84.

Busch, H., von Cranach, M., Gulbinat, W., Renfordt, E., Tegeler, J., 1980. Reliability of the AMDP-system. A preliminary report on a multicentre exercise on the reliability of psychopathological assessment. Acta Psychiatr. Scand. 62, 382-392.

Byers, A.L., Yaffe, K., 2011. Depression and risk of developing dementia. Nat. Rev. Neurol. 7, 323-331.

Chen, P., Ganguli, M., Mulsant, B.H., DeKosky, S.T., 1999. The temporal relationship between depressive symptoms and dementia: a community-based prospective study. Arch. Gen. Psychiatry 56, 261-266.

Chen, R., Hu, Z., Wei, L., Qin, X., McCracken, C., Copeland, J.R., 2008. Severity of depression and risk for subsequent dementia: cohort studies in China and the UK. Br. J. Psychiatry 193, 373-377.

Cooper, B., Holmes, C., 1998. Previous psychiatric history as a risk factor for late-life dementia: a population-based case-control study. Age Ageing 27, 181-188.

Coryell, W., Winokur, G., Shea, T., Maser, J.D., Endicott, J., Akiskal, H.S., 1994. The long-term stability of depressive subtypes. Am. J. Psychiatry 151, 199-204.

DalForno, G., Palermo, M.T., Donohue, J.E., Karagiozis, H., Zonderman, A.B., Kawas, C. H., 2005. Depressive symptoms, sex, and risk for Alzheimer's disease. Annu. Neurol. 57, 381-387.

Delis, D.C., Kramer, J.H., Kaplan, E., Ober, B.A., 1987. The California Verbal Learning Test: Research Edition Adult Version. The Psychological Corporation, San Antonio.

Dotson, V.M., Beydoun, M.A., Zonderman, A.B., 2010. Recurrent depressive 
symptoms and the incidence of dementia and mild cognitive impairment. Neurology 75, 27-34.

Eysenck, H.J., Eysenck, S.B.G., 1975. Manual of the Eysenck Personality Questionnaire. Hodder and Stoughton, London.

Fine, J.P., Gray, R.J., 1999. A proportional hazards model for the subdistribution of a competing risk. J. Am. Stat. Assoc. 94, 496-509.

Finsterwald, C., Alberini, C.M., 2013. Stress and glucocorticoid receptor-dependent mechanisms in long-term memory: from adaptive responses to psychopathologies. Neurobiol. Learn Mem. (pii: S1074-7427(13)00194-9)

Garcia, C., 1984. Doença de Alzheimer, problemas do diagnóstico clínico. Tese de Doutoramento. Faculdade De Medicina DE Lisboa, Lisbon.

Gatz, J.L., Tyas St, S.L., John, P., Montgomery, P., 2005. Do depressive symptoms predict Alzheimer's disease and dementia? J. Gerontol. A Biol. Sci. Med. Sci. 60, 744-747.

Geerlings, M.I., den Heijer, T., Koudstaal, P.J., Hofman, A., Breteler, M.M., 2008. History of depression, depressive symptoms, and medial temporal lobe atrophy and the risk of Alzheimer disease. Neurology 70, 1258-1264.

Green, R.C., Cupples, L.A., Kurz, A., Auerbach, S., Go, R., Sadovnick, D., Duara, R., Kukull, W.W., Chui, H., Edeki, T., Griffith, P.A., Friedland, R.P., Bachman, D., Farrer, L., 2003. Depression as a risk factor for Alzheimer disease: the MIRAGE study. Arch. Neurol. 60, 753-759.

Guy, W., 1976. ECDEU Assessment Manual for Psychopharmacology. Department of Health, Education, and Welfare, Rockville, MD, U.S.

Hasler, G., Drevets, W.C., Manji, H.K., Charney, D.S., 2004. Discovering endophenotypes for major depression. Neuropsychopharmacology 29, 1765-1781.

Irie, F., Masaki, K.H., Petrovitch, H., Abbott, R.D., Ross, G.W., Taaffe, D.R., Launer, L.J., White, L.R., 2008. Apolipoprotein E $\varepsilon 4$ allele genotype and the effect of depressive symptoms on the risk of dementia in men: the Honolulu-Asia aging study. Arch. Gen. Psychiatry 65, 906-912.

Jorm, A.F., 2001. History of depression as a risk factor for dementia: an updated review. Aust. N.Z. J. Psychiatry 35, 776-781.

Kessing, L.V., 2012. Depression and the risk for dementia. Curr. Opin. Psychiatry 25, 457-461.

Kessing, L.V., Nilsson, F.M., 2003. Increased risk of developing dementia in patients with major affective disorders compared to patients with other medical illnesses. J. Affect. Disord. 73, 261-269.

Kessing, L.V., Andersen, P.K., 2004. Does the risk of developing dementia increase with the number of episodes in patients with depressive disorder and in patients with bipolar disorder? J. Neurol. Neurosurg. Psychiatry 75, 1662-1666.

Kessing, L.V., Olsen, E.W., Mortensen, P.B., Andersen, P.K., 1999. Dementia in affective disorder: a case-register study. Acta Psychiatr. Scand. 10, 176-185.

Kupfer, D.J., Frank, E., Phillips, M.P., 2012. Major depressive disorder: new clinical, neurobiological, and treatment perspectives. Lancet 379, 1045-1055.

Lamers, F., Vogelzangs, N., Merikangas, K., de Jonge, P., Beekman, A.T., Penninx, B.W., 2013. Evidence for a differential role of HPA-axis function, inflammation and metabolic syndrome in melancholic versus atypical depression. Mol. Psychiatry $23,1-8$.

Lenoir, H., Dufouil, C., Auriacombe, S., Lacombe, J.M., Dartigues, J.F., Ritchie, K., Tzourio, C., 2011. Depression history, depressive symptoms, and incident dementia: the 3C study. J. Alzheimers Dis. 26, 27-38.

Lin, K., Xu, G., Lu, W., Ouyang, H., Dang, Y., Lorenzo-Seva, U., Guo, Y., Bessonov, D., Akiskal, H.S., So, K.F., Lee, T.M., 2014. Neuropsychological performance in melancholic, atypical and undifferentiated major depression during depressed and remitted states: a prospective longitudinal study. J. Affect. Disord. 168, 184-191.

Lupien, S.J., Maheu, F., Tu, M., Fiocco, A., Schramek, T.E., 2008. The effects of stress and stress hormones on human cognition: implications for the field of brain and cognition. Brain Cogn. 65, 209-237.

Lupien, S.J., de Leon, M., de Santi, S., Convit, A., Tarshish, C., Nair, N.P., Thakur, M., McEwen, B.S., Hauger, R.L., Meaney, M.J., 1998. Cortisol levels during human aging predict hippocampal atrophy and memory deficits. Nat. Neurosci. 1, 69-73.

Madureira, S., Verdelho, A., Ferro, J., Basile, A.M., Chabriat, H., Erkinjuntti, T., Fazekas, F., Hennerici, M., O'brien, J., Pantoni, L., Salvadori, E., Scheltens, P., Visser, M. C., Wahlund, L.O., Waldemar, G., Wallin, A., Inzitari, D., 2006. Development of a neuropsychological battery for the Leukoaraiosis and Disability in the Elderly Study (LADIS): experience and baseline data. Neuroepidemiology 27, 101-116 (LADIS Study Group).

Malhi, G.S., Bassett, D., Boyce, P., Bryant, R., Fitzgerald, P.B., Fritz, K., Hopwood, M., Lyndon, B., Mulder, R., Murray, G., Porter, R., Singh, A.B., 2015. Royal Australian and New Zealand College of Psychiatrists clinical practice guidelines for mood disorders. Aust. N.Z. J. Psychiatry 49, 1087-1206.

Martínez-Arán, A., Vieta, E., Colom, F., Torrent, C., Sánchez-Moreno, J., Reinares, M., Benabarre, A., Goikolea, J.M., Brugué, E., Daban, C., Salamero, M., 2004. Cognitive impairment in euthymic bipolar patients: implications for clinical and functional outcome. Bipolar Disord. 6, 224-232.

McEwen, B.S., Magariños, A.M., 1997. Stress effects on morphology and function of the hippocampus. Annu. N.Y. Acad. Sci. 821, 271-284.

McKeith, I.G., Dickson, D.W., Lowe, J., Emre, M., O'Brien, J.T., Feldman, H., Cummings, J., Duda, J.E., Lippa, C., Perry, E.K., Aarsland, D., Arai, H., Ballard, C.G., Boeve, B., Burn, D.J., Costa, D., Del Ser, T., Dubois, B., Galasko, D., Gauthier, S., Goetz, C.G., Gomez-Tortosa, E., Halliday, G., Hansen, L.A., Hardy, J., Iwatsubo, T., Kalaria, R.N., Kaufer, D., Kenny, R.A., Korczyn, A., Kosaka, K., Lee, V.M., Lees, A., Litvan, I. Londos, E., Lopez, O.L., Minoshima, S., Mizuno, Y., Molina, J.A., Mukaetova-Ladinska, E.B., Pasquier, F., Perry, R.H., Schulz, J.B., Trojanowski, J.Q., Yamada, M., 2005. Diagnosis and management of dementia with Lewy bodies: third report of the DLB Consortium. Neurology 65, 1863-1872 (Consortium on DLB).
McKhann, G.M., Knopman, D.S., Chertkow, H., Hyman, B.T., Jack Jr, C.R., Kawas, C.H., Klunk, W.E., Koroshetz, W.J., Manly, J.J., Mayeux, R., Mohs, R.C., Morris, J.C., Rossor, M.N., Scheltens, P., Carrillo, M.C., Thies, B., Weintraub, S., Phelps, C.H., 2011. The diagnosis of dementia due to Alzheimer's disease: recommendations from the National Institute on Aging-Alzheimer's association workgroups on diagnostic guidelines for Alzheimer's disease. Alzheimers Dement, 3263-3269.

Mendelsohn, D., 2000. Test de Toulouse-Pieron aplicado a jugadores de fútbol profesional Club El Porvenir, años 1996/98. EF y Deportes. Recover 18, 2004 〈http://www.efdeportes.com/efd18a/toulouse.htm〉.

Norton, S., Matthews, F.E., Barnes, D.E., Yaffe, K., Brayne, C., 2014. Potential for primary prevention of Alzheimer's disease: an analysis of population-based data. Lancet Neurol. 13, 788-794.

Ownby, R.L., Crocco, E., Acevedo, A., John, V., Loewenstein, D., 2006. Depression and risk for Alzheimer disease: systematic review, meta-analysis, and metaregression analysis. Arch. Gen. Psychiatry 63, 530-538.

Paes de Sousa, M., Souto Lopes, J., Figueira, L., Nicolau, M.H., Roldão Vieira, C., 1980 Cluster analysis in the study of depressive classification (therapeutic aspects). Acta Psiquiátrica Port. 26, 21-35.

Parker, G., Paterson, A., 2014. Melancholia: definition and management. Curr. Opin. Psychiatry 27, 1-6.

Parker, G., McCraw, S., Blanch, B., Hadzi-Pavlovic, D., Synnott, H., Rees, A.M., 2013. Discriminating melancholic and non-melancholic depression by prototypic clinical features. J. Affect. Disord. 144, 199-207.

Rascovsky, K., Hodges, J.R., Knopman, D., Mendez, M.F., Kramer, J.H., Neuhaus, J., van Swieten, J.C., Seelaar, H., et al., 2011. Sensitivity of revised diagnostic criteria for the behavioural variant of frontotemporal dementia. Brain 134 (Pt 9), 2456-2477.

Reitan, R.M., 1958. Validity of the trail making test as an indicator of organic brain damage. Percept. Mot. Skills 8, 271-276.

Reitz, C., Brayne, C., Mayeux, R., 2011. Epidemiology of Alzheimer disease. Nat. Rev. Neurol. 7, 137-152.

Ribeiro, F., Guerreiro, M., de Mendonça, A., 2007. Verbal learning and memory deficits in Mild Cognitive Impairment. J. Clin. Exp. Neuropsychology 29, 187-197.

Ritchie, K., Carriére, I., Ritchie, C.W., Berr, C., Artero, S., Ancelin, M.-L., 2010. Designing prevention programmes to reduce incidence of dementia: prospective cohort study of modifiable risk factors. BMJ 341, c3885.

Roca, M., Monzón, S., Vives, M., López-Navarro, E., Garcia-Toro, M., Vicens, C., Garcia-Campayo, J., Harrison, J., Gili, M., 2015. Cognitive function after clinical remission in patients with melancholic and non-melancholic depression: a 6 month follow-up study. J. Affect. Disord. 171, 85-92.

Roman, G.C., Tatemichi, T.K., Erkinjuntti, T., Cummings, J.L., Masdeu, J.C., Garcia, J.H., Amaducci, L., Orgogozo, J.M., Brun, A., Hofman, A., et al., 1993. Vascular dementia: diagnostic criteria for research studies. Report of the NINDS-AIREN international workshop. Neurology 43, 250-260.

Sachs-Ericsson, N., Moxley, J.H., Corsentino, E., Rushing, N.C., Sheffler, J., Selby, E.A., Gotlib, I., Steffens, D.C., 2014. Melancholia in later life: late and early onset differences in presentation, course, and dementia risk. Int. J. Geriatr. Psychiatry 29, 943-951.

Saczynski, J.S., Beiser, A., Seshadri, S., Auerbach, S., Wolf, P.A., Au, R., 2010. Depressive symptoms and risk of dementia: the Framingham heart study. Neurology $75,35-41$.

Salvatore, P., Khalsa, H.M., Hennen, J., Tohen, M., Yurgelun-Todd, D., Casolari, F., Depanfilis, C., Maggini, C., Baldessarini, R.J., 2007. Psychopathology factors in first-episode affective and non-affective psychotic disorders. J. Psychiatr. Res. 41, 724-736.

Saracci, R., 2006. Survival-related biases survive well. Int. J. Epidemiol. 36, 244-246.

Seemüller, F., Riedel, M., Wickelmaier, F., Adli, M., Mundt, C., Marneros, A., Laux, G. Bender, W., Heuser, I., Zeiler, J., Gaebel, W., Jäger, M., Möller, H.J., Henkel, V., 2008. Atypical symptoms in hospitalized patients with major depressive episode: frequency, clinical characteristics, and internal validity. J. Affect. Disord. 108, 271-278.

Silva, J., Gonçalves-Pereira, M., Xavier, M., Mukaetova-Ladinska, E.B., 2013. Affective disorders and risk of developing dementia: systematic review. Br. J. Psychiatry 202, 177-186.

Silverman, J.M., Breitner, J.C., Mohs, R.C., Davis, K.L., 1986. Reliability of the family history method in genetic studies of Alzheimer's disease and related dementias. Am. J. Psychiatry 143, 1279-1782.

Steffens, D.C., Plassman, B.L., Helms, M.J., Welsh-Bohmer, K.A., Saunders, A.M., Breitner, J.C., 1997. A twin study of late-onset depression and apolipoprotein E epsilon 4 as risk factors for Alzheimer's disease. Biol. Psychiatry 41, 851-856.

Suzuki, A., Poon, L., Papadopoulos, A.S., Kumari, V., Cleare, A.J., 2014. Long term effects of childhood trauma on cortisol stress reactivity in adulthood and relationship to the occurrence of depression. Psychoneuroendocrinology 50, 289-299.

Taylor, M.A., Fink, M., 2008. Restoring melancholia in the classification of mood disorders. J. Affect. Disord. 105, 1-14.

Teixeira, J., Pereira, A., de Mendonça, A., Simões do Couto, F., 2011. Validation of Silverman Dementia Questionnaire to the Portuguese Population. Poster presented to the 25th Meeting of Grupo de Estudos de Envelhecimento Cerebral e Demência, Luso, Portugal.

Toulouse, Y., Piéron, H., 1986. Prueba perceptiva y de atención. Tea Ediciones Madrid.

Wang, H.X., Karp, A., Herlitz, A., Crowe, M., Kareholt, I., Winblad, B., Fratiglioni, L., 2009. Personality and lifestyle in relation to dementia incidence. Neurology 72 253-259. 
Wilson, R.S., Schneider, J.A., Bienias, J.L., Arnold, S.E., Evans, D.A., Bennett, D.A., 2003. Depressive symptoms, clinical AD, and cortical plaques and tangles in older persons. Neurology 61, 1102-1107.

Withall, A., Harris, L., Cumming, S., 2010. A longitudinal study of cognitive function in melancholic and non-melancholic subtypes of major depressive disorder. J. Affect. Disord. 123, 150-157.

Wulsin, L.R., Vaillant, G.E., Wells, V.E., 1999. A systematic review of the mortality of depression. Psychosom. Med. 61, 6-17. 